\title{
ESTRUTURA ESPACIAL DA PAISAGEM DA MORRARIA DA PRAIA VERMELHA (SC): SUBSÍDIO À ECOLOGIA DA PAISAGEM
}

\author{
Rosemeri Carvalho Marenzi $^{*}$ Carlos Vellozo Roderjan ${ }^{* *}$ \\ * Eng ${ }^{\mathrm{a}}$. Florestal, Dr ${ }^{\mathrm{a}}$., CTTMar - UNIVALI - merimarenzi@univali.br \\ ** Eng. Florestal, Dr., Depto. de Ciências Florestais, UFPR - roderjan@floresta.ufpr.br \\ Recebido para publicação: 30/05/2004 - Aceito para publicação: 25/08/2005
}

\begin{abstract}
Resumo
Estrutura espacial da paisagem da Morraria da Praia Vermelha (SC): subsídio à ecologia da paisagem. O objetivo deste estudo foi analisar a estrutura espacial da: paisagem como padrão funcional para a biodiversidade, considerando-a como um componente da ecologia da paisagem. Como área de estudo, foi enfocada a Morraria da Praia Vermelha (Penha, SC), sendo utilizado o programa Fragstats Spatial Pattern Analysis (ArcView). Foi verificado que a paisagem é representada por 174 manchas, por corredores compostos de cursos d'água, estradas, trilhas e linha de costão, e pela matriz, constituída por uma mancha de floresta. Espécies arbóreas clímax são raras ou muito raras, resultado da retirada seletiva, redução das aves dispersoras, condições edáficas e inclinação topográfica, conciliada à distância entre as manchas de floresta. A situação da área é ainda mais adversa devido à inexistência de conectividade com outros fragmentos. Se não forem adotadas ações de política pública, considerando a implantação de programas de restauração, de fiscalização e de educação ambiental, a tendência é de perda da biodiversidade ainda existente no ambiente.

Palavras-chave: Ecologia da paisagem; fragmentação de hábitat; conservação da biodiversidade.
\end{abstract}

\begin{abstract}
Spatial structure of "Morraria da Praia Vermelha" landscape (SC): contribution to landscape ecology. This analysis focused on spatial structure of landscape as functional pattern to biodiversity, as a component of landscape ecology. This research focuses on Morraria da Praia Vermelha (Penha, SC) area using Fragstats Spatial Pattern Analysis (ArcView) program. It noticed that the landscape is represented by 174 patches crossed by corridors constituted by rivers, roads, tracks, and cliffs, and a matrix, constituted by a forest patch. Climax arboreal species are rare or very rare, as result of selective removing, decreasing number of dispersive birds, soil conditions and topographic inclination, as weel as distance among forest patches. The situation of the area is still more adverse due to inexistence of conectivity with other fragments. Actions of public policy, as restauration, fiscalization and education programs, must be applied, otherwise still surrendering biodiversity in the area tends to disapear.

Keywords: Landscape ecology; habitat fragmentation; biodiversity conservation .
\end{abstract}

\section{INTRODUÇÃO}

As porções da costa que constituem os promontórios rochosos ainda mantêm certa naturalidade, decorrente da geomorfologia existente. $\mathrm{O}$ aspecto natural dessas áreas, associado à condição edáfica e à dificuldade de acesso, privilegia a manutenção de suas características.

No entanto, essa mesma situação contribui para a fragmentação desses ecossistemas, de condição ambiental semelhante à existente em ilhas, uma vez que a limitação pelo oceano e pela planície costeira no entorno dificulta a conectividade. Dessa forma, espécies da fauna e da flora necessitam adaptar-se a um hábitat mais restrito e sujeito à pressão antrópica.

As ciências compartimentadas nas diversas áreas do conhecimento devem propiciar informações que permitam considerar o sistema complexo e dinâmico, reconhecendo a importância ambiental, social e cultural dos ecossistemas e as transformações ocorrentes.

A Ecologia da Paisagem, que trata do estudo das inter-relações entre os diversos fatores que

FLORESTA, Curitiba, PR, v. 35, n. 2, mai./ago. 2005. 
contribuem na formação das e entre as unidades relativamente homogêneas que formam a paisagem (Rocha, 1995), pode possibilitar o entendimento dos processos naturais e culturais atuantes nos ecossistemas com perspectiva de análise e de planejamento ambiental. Considerando, ainda, que estuda a combinação, a estrutura, a função e as alterações de diferentes ambientes (Forman e Godron, 1986), ela pode contribuir para o entendimento da diversidade biótica existente nos diferentes fragmentos de hábitat.

Em face do exposto, este trabalho teve como objetivo aplicar um modelo de estrutura espacial da paisagem a um promontório costeiro como componente da ecologia da paisagem da área, buscando compreender o seu padrão funcional em relação à manutenção da biodiversidade local.

A abordagem enfocou a localidade conhecida como Morraria da Praia Vermelha, localizada no município de Penha, Santa Catarina, sendo a escolha desse local como estudo de caso decorrente de sua situação como promontório costeiro relativamente conservado, mas naturalmente fragmentado devido a sua constituição geomorfológica, intensificada pela pressão antrópica no entorno.

Este estudo pretendeu possibilitar incluir um componente na reunião de informações para compreender o processo de formação e de utilização de uma paisagem, principalmente no que tange à conservação dos promontórios costeiros.

\section{REVISÃO BIBLIOGRÁFICA}

\section{Ecologia da paisagem}

A base da ecologia da paisagem surgiu de Humboldt (Zonneveld, 1994) e de Darwin (Porto, 1999), sendo que para Turner e Gardner (1991), Malanson (1995), Rocha (1995), Troppmain (2000) e Burel e Baudry (2002), o seu conceito foi introduzido no final da década de 1930 pelo biogeógrafo Carl Troll, formulado com base no potencial apresentado pelo uso de fotografias aéreas, que permitia a observação de paisagens a partir de abordagens ecossistêmicas, como síntese entre a ecologia e a geografia.

Dos muitos conceitos de paisagem, os mais atuais a definem como sendo a expressão do produto de interação espacial e temporal do indivíduo com o meio (UICN, 1984). Para Rocha (1995), a paisagem é fruto da interação dos componentes geológicos, expostos à ação do clima e a fatores geomorfológicos, bióticos e antrópicos através dos tempos, refletindo hoje o registro acumulado da evolução biofísica e da história das culturas precedentes.

A ecologia da paisagem considera a paisagem de maneira holística, na dimensão ecológica, considerando seus aspectos culturais, sociais, políticos e ambientais, cujos enfoques vão depender do detalhamento que se necessite ou do caráter do estudo a ser realizado, assim como da escala de trabalho (Forman e Godron, 1981; Turner et al., 1989; Turner et al., 1991; Forman, 1995; Rocha, 1995; Porto, 1999; Mazzer, 2001).

De acordo com Forman e Godron (1986), a ecologia da paisagem considera a estrutura, a função e a alteração do ecossistema. A estrutura se refere às relações espaciais entre ecossistemas distintos, analisando a distribuição de energia, materiais e espécies em relação ao tamanho, forma, quantidade, tipos e configuração dos componentes. A função diz respeito à interação entre os elementos espaciais, isto é, o fluxo de energia, materiais e espécies entre os componentes ecossistêmicos. A alteração se refere à mudança na estrutura e na função do mosaico ecológico (Turner e Gardner, 1991), considerando que a dinâmica paisagística depende das relações entre as sociedades e seu ambiente, criando estruturas modificadas no espaço e no tempo, e que essa heterogeneidade controla numerosos movimentos e fluxos de organismos, matéria e energia (Burel e Baudry, 2002).

Para Malanson (1995), a ecologia da paisagem é baseada na hipótese de que as interações entre os componentes bióticos e abióticos são espacialmente mensuráveis, sendo que Primack e Rodrigues (2001) atestam a importância do conhecimento dessas interações para a proteção da diversidade biológica.

\section{Estrutura espacial da paisagem}

Os elementos componentes da estrutura da paisagem foram percutidos primeiramente nos livros "Patches and Structural Components for a Landascape Ecology" (Forman e Godron, 1981) e "Landscape Ecology" (Forman e Godron, 1986), os quais os distinguiam como: matrix, corridors e patches. 
Os componentes matrix e corridors foram traduzidos na literatura científica espanhola e portuguesa como matriz e corredores. No entanto, para o termo patches ainda não existe uma concordância na tradução, podendo ser utilizados: unidades de paisagem, fragmentos e manchas.

$\mathrm{O}$ termo unidades de paisagem parece ser mais utilizado em trabalhos relacionados à qualidade visual da paisagem, como em Jordana (1992), Pires (1993), Rocha (1995) e Marenzi (1996). Outros autores adotaram o termo mancha, entre os quais Polette (1999), Mazzer (2001), Terradas (2001), Anjos (2001) e Burel e Baudry (2002).

Neste trabalho também é adotado o termo mancha, seguindo a fundamentação teórica do livro "Ecologia del Paisage" (Burel e Baudry, 2002), considerando que é uma bibliografia recente e completa, seguidora de Forman e Godron (precursores do método), e a que mais se aproxima da língua portuguesa, existindo uma tendência de padronização de uso para os países latinos. Dessa forma, consideramos como componentes: matriz, corredores e manchas (Figura 1).

O termo fragmento, usual em estudos de Biologia de Conservação, neste trabalho se refere à paisagem da área total da Morraria da Praia Vermelha, que é uma área constituída de uma série de manchas e de corredores, somada a outros fragmentos que compõem a região do entorno. Assim, em uma escala local, a Morraria é uma área fragmentada, formada por um conjunto de manchas e de corredores, por isso percebida como fragmento e tratada, neste trabalho, como paisagem.

Segundo Burel e Baudry (2002), um padrão paisagístico é constituído de um mosaico formado de manchas e de uma rede formada de corredores, os quais mantêm uma borda em seus limites, que interage com a matriz.

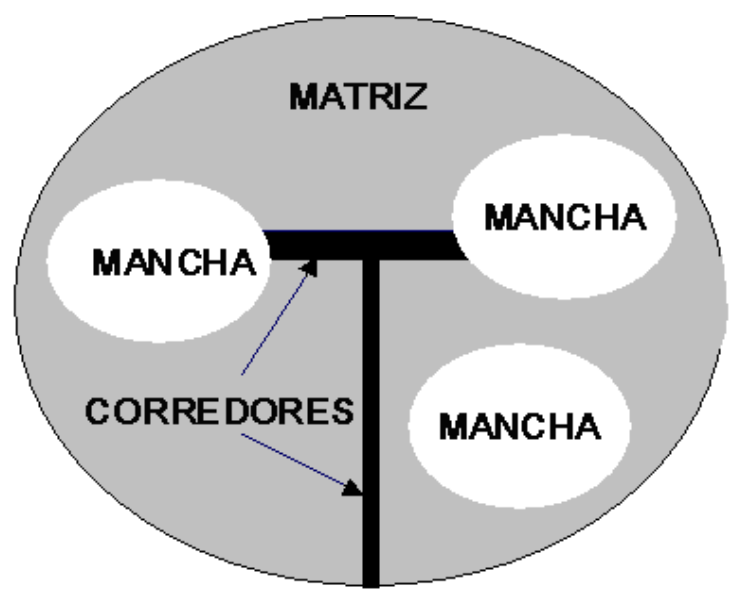

Fonte: Adaptado de Burel e Baudry (2002, p. 71).

Figura 1. Elementos da estrutura da paisagem.

Figure 1. Elements of landscape structure.

\section{Matriz}

A Matriz é o elemento dominante, controlando o funcionamento e a dinâmica da paisagem (Forman e Godron, 1986; Forman, 1995; Rocha, 1995; Mazzer, 2001; Burel e Baudry, 2002), considerando a manutenção da formação fitoecológica, que sustenta toda a diversidade biológica.

A matriz geralmente tem composição homogênea, e dos elementos da paisagem é a mais extensa e a mais conectada, mantendo maior controle funcional sobre a área (Forman e Godron, 1981; Forman, 1995). Dessa forma, qualquer mudança na paisagem é determinada por essas características (Mazzer, 2001).

\section{Manchas}

Manchas se referem à reunião de espécies em um local predominado por uma matriz, que possui composição de comunidade distinta (Forman e Godron, 1981; Forman, 1995), diferindo da área adjacente (Carmo, 2000), e que podem manter conectividade através dos corredores. 
Para Mazzer (2001), a mancha representa um domínio espacial ou temporal de condições ambientais relativamente homogêneas, sendo os limites da mancha distinguidos por descontinuidades ambientais relevantes para um organismo ou um processo ecológico em questão.

\section{Corredores}

Os Corredores consistem na rede de ligação através do sistema viário (estradas e trilhas) e de drenagem (córregos e canais), sendo que a disposição espacial do mosaico de manchas e de redes constitui o padrão paisagístico que possibilita a conectividade entre os organismos existentes (Matteucci, 1998; Burel e Baudry, 2002).

Para Forman e Godron (1981; 1986), os corredores podem ser de três tipos: Linhas-Corredores, de forma linear (estradas, trilhas, cercas, diques, canais e outros); Faixas-Corredores, mais largas que as linhas e usualmente com presença de vegetação (auto-estradas, sistemas de torres de energia); e Cursos d'água, principalmente considerando a vegetação ao longo dos mesmos.

Cada um desses corredores difere em sua função ecológica e sua utilização por diferentes e múltiplos organismos, desde plantas, animais e humanos (Mazzer, 2001), dependendo da sua largura e sua conectividade (Forman e Godron, 1981; Forman e Godron, 1986; Forman, 1995).

As funções ecológicas dos corredores são descritas por Forman (1995) como:

a) Hábitat - o microclima e a área de borda existente propiciam condições de hábitat para espécies generalistas, invasoras e algumas introduzidas.

b) Condutor - a forma linear tende a produzir fluxos no mesmo sentido, propiciando uma condução natural.

c) Filtro - a limitação entre manchas e matriz pode inibir a presença de algumas espécies, assim como a permeabilidade pode possibilitar a passagem de outras, dependendo do gradiente ambiental da borda e das espécies existentes.

d) Fonte - os organismos que se movimentam ou se estabelecem nos corredores representam recursos para a matriz adjacente, promovendo a heterogeneidade.

e) Sumidouro - o desaparecimento de organismos, sedimentos, sementes e outros componentes, carreados para o corredor e morrendo ou ficando inativos por não encontrarem condições adequadas. O fluxo fluvial, o vento, a neve, ou outros fatores podem acumular material nos corredores, tornando os animais mais expostos a predadores no ambiente mais aberto.

\section{Borda e limites}

As bordas e limites são áreas que margeiam as manchas, os corredores e as matrizes de uma paisagem. Mazzer (2001) as define como gradientes abruptos entre elementos da estrutura da paisagem, os quais possuem funções especiais dentro da paisagem conforme suas variações. Para Gascon et al. (2001), a borda deve ser distinguida do ecótone (gradiente natural entre dois tipos de hábitat), sendo a diferença básica o grau de contraste entre os dois hábitats. Na área fragmentada, esse contraste é abrupto.

Já os limites podem ser de abruptos a suaves, e retos ou curvilíneos, e através dessas combinações podem apresentar padrões diferentes. Em relação às bordas, há a possibilidade de funções semelhantes às dos corredores (hábitat, condutor, filtro, fonte e sumidouro), sendo que o efeito filtro é relacionado à permeabilidade da borda, determinada pela estrutura vertical das espécies vegetais existentes. Essa estrutura é denominada de textura da borda e controla o fluxo de energia, matéria e organismos e as perturbações entre matriz e manchas ou matriz e corredores, controlando a heterogeneidade do sistema (Forman, 1995).

\section{MATERIAL E MÉTODOS}

\section{Análise do uso do solo}

Para a análise do uso do solo, utilizou-se o mapeamento de fitofisionomia e uso do solo, elaborado a partir de fotografias aéreas verticais, pancromáticas, em escala 1:8.000, de 2.000, disponibilizadas pela CELESC (Centrais Elétricas de Santa Catarina). Essas fotografias foram rasterizadas em scanner de mesa a fim de serem trabalhadas em meio digital. 
Através da utilização do software Corel Draw 10, foi realizado o recorte da área central de cada fotografia, as quais foram registradas (georreferenciadas) no software ENVI 3.2, utilizando a base cartográfica digital cedida por ACAPRENA, que resultou, devido à diferenciação de escala, em um erro médio (RMS - Root Minimun Square) de 10 metros.

Em posse dessas imagens, devidamente registradas, foi gerado o mosaico controlado das imagens, que resultou em uma única imagem de toda a área de estudo.

No intuito da elaboração de um mapa temático de fitofisionomia e uso do solo, o mosaico foi passado para ambiente SIG (software ArcView 3.2), onde foram digitalizados diferentes polígonos, que delimitam as diferentes tipologias de vegetação (floresta, estágios sucessionais e outros) e do uso do solo (urbanização, pastagem e outros), previamente definidas.

\section{Análise da fitofisionomia}

Como esta pesquisa visou uma caracterização das tipologias existentes com base nas espécies dominantes fisionomicamente, sem encerrar a identificação de espécies vegetais ocorrentes, foi utilizado o Método Expedito de Levantamento não Sistemático de Caminhamento (Filgueiras et al., 1994).

Foram percorridas estradas, trilhas já traçadas e picadas abertas em locais normalmente não freqüentados, sendo que o reconhecimento das espécies arbóreas em campo teve o auxílio de um "mateiro" local. No caso de identificações duvidosas, foi coletado material contendo parte da ramificação, de preferência fértil, para confirmação comparativa com a bibliografia.

\section{Análise da estrutura espacial da paisagem}

O critério de definição das manchas teve como base a homogeneidade das tipologias vegetais (Schwabe 1991; Mazzer 2001), correspondendo às biocenoses (Godron, 1994), também conhecidas por biótopos (FEEMA, 1992), originadas do uso dos solos como resultado da interferência humana no sistema biótico. Os corredores foram determinados pelo desenho do traçado das estradas, das trilhas e dos cursos d'água existentes na área. A matriz, pelo critério de mancha dominante na paisagem.

A composição estrutural foi derivada do mapa de fitofisionomia e de uso do solo, sendo utilizado o SIG Arcview 3.2 para integrar determinadas tipologias que funcionam como diferentes hábitats, formando um outro conjunto de tipologias, denominadas de manchas, representadas em uma nova cartografia, definida como mapa de estrutura espacial da paisagem, contemplando um mosaico em conjunto com os corredores.

A partir da disposição cartográfica do arranjo dos elementos básicos (matriz, manchas e corredores), foi utilizado o programa Fragstats Spatial Pattern Analysis, desenvolvido por McGarigal e Marks, em 1994 (Elkie et al., 1999). Esse programa é específico para análise de fragmentação de paisagem através da extensão Patch Analyst, instalada no Arcview, possibilitando a obtenção das seguintes variáveis descritivas da paisagem: Área e Quantidade de Manchas, Densidade de Borda, Índice de Forma, Índice de Continuidade, Índice de Diversidade e Índice de Eqüitabilidade.

\section{RESULTADOS E DISCUSSÃO}

\section{Matriz da paisagem}

Tendo em vista a situação da área estudada, foram eleitas nove manchas como mais relevantes para a manutenção da biodiversidade local, e definida como matriz a área de floresta, representada pela mancha denominada de número 1 (Figura 2), sendo este o elemento dominante que controla o funcionamento e a dinâmica da paisagem.

Em função da situação geomorfológica de promontório da área estudada, todas as manchas situadas na face oriental recebem interferência do Oceano Atlântico. A influência marinha pela ação direta das marés (salinidade e instabilidade espacial) ocorre principalmente na duna frontal e no costão, mas toda a restinga é influenciada pela atuação climática (intensidade de ventos e de temperatura) e pela condição edáfica (solo arenoso e de pouca umidade).

Essa influência atua também na matriz, pela conectividade com esses ambientes, cuja forma estreita e alongada propicia certa permeabilidade. Essa influência afeta a fisionomia da matriz, que é constituída de Floresta Ombrófila Densa, sendo visualmente perceptível pelos troncos e ramos retorcidos das árvores pela ação do vento. 


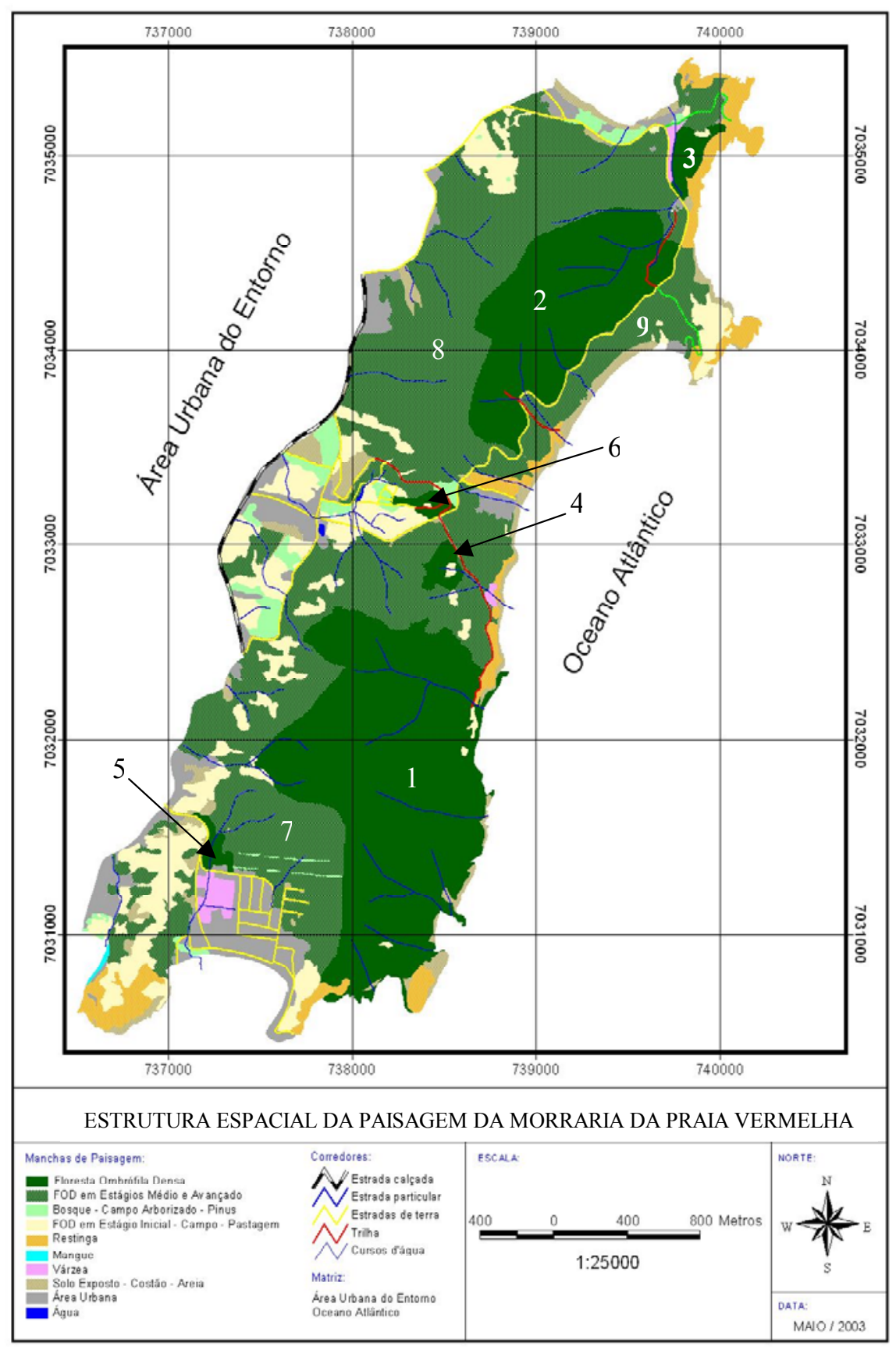

Figura 2. Estrutura espacial da paisagem da Morraria da Praia Vermelha. Figure 2. Spatial structure of Morraria da Praia Vermelha landscape.

É possível supor que essa mesma influência oceânica (ventos, correntes) traga conseqüências para a fauna, principalmente em dias de maior intensidade de vento e em indivíduos de menor porte, que se obrigam a encontrar abrigo mais no interior da floresta, portanto, na matriz. 
A matriz pode propiciar dispersão para o enriquecimento da mancha de vegetação secundária e para a manutenção da mancha de restinga (nesta, principalmente por meio dos indivíduos arbóreos comuns aos dois ambientes).

A conservação da matriz se dá em função de não existir em seu interior nenhum corredorestrada, apenas corredor-trilha, que acompanha a linha da costa, e por conter onze (11) cursos d'água, todos mantendo mata ciliar, com possibilidade de nichos potenciais existentes em um ambiente de floresta, propiciando abrigos e alimentos à biodiversidade.

A matriz representa a maior área em mancha, igual a 150,83 ha (21\% do total), estando margeada em grande parte pela mancha de vegetação em estágio avançado de regeneração, segunda mancha em área $(133,13$ ha - 17\%), e, na face leste, pelas manchas de costão e de restinga (vegetação de solo arenoso e rochoso).

\section{Manchas da paisagem}

A área da paisagem totaliza 762,46 ha, cujas tipologias, originadas do mapa de fitofisionomia e de uso do solo, foram agrupadas em 174 polígonos, chamados de manchas de paisagem (Figura 2), significando 10 classes de manchas quanto à função de hábitats para a biodiversidade.

\section{Corredores da paisagem}

Os corredores considerados na paisagem se referem à drenagem a ao traçado do sistema viário (Tabela 1), sendo esse formado apenas por linhas-corredores.

Tabela 1. Situação dos corredores existentes na Morraria da Praia Vermelha.

Table 1. Situation of corridors present in Morraria da Praia Vermelha.

\begin{tabular}{|c|c|c|}
\hline Tipo de Corredor & Características & Função \\
\hline $\begin{array}{l}\text { Estrada Calçada } \\
\text { (paralelepípedo) }\end{array}$ & 2262 m de extensão, situada no limite ocidental da área. & Filtro e Sumidouro \\
\hline Estrada de Terra & $\begin{array}{l}15.705 \text { metros de extensão. Parte adentra na Morraria pela } \\
\text { porção sul e parte adentra na porção central, seguindo pela } \\
\text { linha da costa oriental até o norte, e novamente para o } \\
\text { ocidente da área. }\end{array}$ & Condutor, Filtro e Sumidouro \\
\hline Estrada Particular & $\begin{array}{l}\text { Consideradas apenas as duas mais significativas em } \\
\text { extensão e por percorrerem ambientes naturais, uma de } 615 \\
\text { metros e outra de } 586 \text { metros. }\end{array}$ & Condutor, Filtro e Sumidouro \\
\hline Trilha & $\begin{array}{l}\text { Corresponde a seis traçados abertos, distribuídos em } \\
\text { imóveis particulares, sendo quatro deles situados em } \\
\text { ambiente de floresta, dos quais, duas trilhas dão passagem } \\
\text { para o mar; em média com um metro de largura, e } \\
\text { totalizando } 2798 \text { metros. }\end{array}$ & Condutor e Sumidouro \\
\hline Linha de Costão & $\begin{array}{l}\text { Acompanha a orla marítima, sendo interrompida em alguns } \\
\text { trechos pela descontinuidade de rochas e presença de } \\
\text { enseadas. }\end{array}$ & $\begin{array}{l}\text { Hábitat, Condutor, Fonte } \\
\text { Filtro }\end{array}$ \\
\hline Mata Ciliar & $\begin{array}{l}\text { Principalmente em áreas constituídas de floresta e de } \\
\text { vegetação em estágio avançado. }\end{array}$ & Hábitat, Condutor e Fonte \\
\hline Curso d'água & $\begin{array}{l}\text { Corresponde a } 45 \text { (quarenta e cinco) cursos d'água, } \\
\text { distribuídos ao longo das diversas vertentes. }\end{array}$ & $\begin{array}{l}\text { Hábitat, Condutor, } \\
\text { Filtro e Sumidouro }\end{array}$ \\
\hline
\end{tabular}

Forman e Collinge (1996) incluem como benefícios da existência de vegetação nas margens dos rios: o controle de erosão nas margens, a redução de nutrientes e outras substâncias que entrariam no córrego, mas que permanecem no sistema, a possibilidade de abrigo e de condução das espécies que se movem pelo sistema, o fornecimento de sombra e de alimentos, também pelas folhas e troncos caídos.

Malanson (1995) salienta a importância da dinâmica fluvial dos cursos d'água para a diversidade biológica, sendo que o próprio rio define duas extremidades de elementos da paisagem ribeirinha que compartilham algumas características com a floresta, pois as condições de microclima, em função dos efeitos de radiação solar e de velocidade do vento, são diferenciadas nas extremidades dos cursos d'água, que atuam como efeito de borda. 


\section{Estrutura espacial e o padrão funcional da paisagem}

A paisagem local da Morraria da Praia Vermelha é tida como um fragmento e contém diversas manchas, que podem ser consideradas como subfragmentos em seu interior. Hobbs et al. (1993) ressaltam que a fragmentação causa efeitos na vegetação - decorrentes da redução de área, das mudanças na composição e estrutura -, na fauna, no regime hídrico e na invasão de espécies exóticas, estas ocupando as clareiras abertas. Quanto aos efeitos na avifauna, citam casos de aumento de populações pela expansão do espaço aberto, mas que pode também ocorrer a introdução de mamíferos herbívoros e predadores, que certamente trazem significativo impacto às aves.

Alguns dados que podem contribuir para um melhor entendimento do padrão funcional da paisagem para a biodiversidade da área constam na Tabela 2.

Tabela 2. Valores da estrutura espacial da paisagem na Morraria da Praia Vermelha.

Table 2. Spatial structure values of Morraria da Praia Vermelha landscape.

\begin{tabular}{lrll}
\hline $\begin{array}{l}\text { Paisagem local } \\
\text { Características }\end{array}$ & Índices & \\
\hline Área (ha) & 762,46 & Forma & 1,89 \\
Manchas $\left(\mathrm{n}^{\circ}\right)$ & 174,00 & Diversidade & 4,22 \\
Classes de Manchas $\left(\mathrm{n}^{\circ}\right)$ & 10,00 & Eqüitabilidade & 0,82 \\
Perímetro (m) & $184.253,50$ & Contágio & 3,72 \\
Densidade de Borda (m/ha) & 241,65 & & \\
\hline
\end{tabular}

Apesar de não existir um consenso sobre a área mínima para a conservação da biodiversidade, e sim a necessidade de uma Área Mínima Viável (AMV) para uma População Mínima Viável (PMV), o estabelecimento da eficiência no tamanho de uma área deve se dar de acordo com a população que se deseja manter sustentável. Considerando-se o proposto por Carmo (2000), que áreas maiores que 300 ha tem um alto valor para a conservação, a área da Morraria atende a esse padrão. No entanto, é preciso considerar a relação entre área e tipologia de vegetação, pois a composição vegetal é limitante na manutenção ou na recuperação das espécies bióticas desejadas.

O significado do valor de densidade de borda se justifica quando da comparação com outras áreas que dividem um mesmo espaço. No caso da paisagem como um todo, cuja densidade de borda se refere à relação entre seu perímetro e sua área, é possível comparar com uma área circular, cujo perímetro é o menor possível para uma mesma área. Nesse caso, na Morraria da Praia Vermelha, de área igual a 762,46 ha, um perímetro de 9784 metros pode resultar numa densidade de borda igual a 12,83. Portanto, comparando ao resultado de 241,65 para a paisagem estudada, revela um valor alto, indicando um significativo efeito de borda para toda a área.

Entretanto, o índice de forma é menor que 2, indicando que a forma do fragmento tende a uma superfície agregada, de eficiência alta na conservação da biodiversidade, considerando uma menor interação com o entorno.

O intercâmbio com a matriz, no caso da Morraria, é um efeito desejado em função de que a interferência é positiva. No entanto, a permeabilidade entre esta e as manchas na face leste contribui com as condições adversas da influência marinha, interferindo na própria matriz, como também interfere a pressão antrópica de uma planície ocupada na face oeste. Sendo assim, apesar do perímetro indicar um efeito de borda significativo para a área, a forma agregada preserva mais o interior da matriz.

A heterogeneidade da paisagem se refere à diversidade existente. $O$ índice de 4,22 indica uma alta riqueza de tipos de manchas, se comparado ao resultado de 2,18, obtido por Carmo (2000) para uma paisagem tropical na Costa Rica. O índice de eqüitabilidade, de 0,82 , se aproxima do obtido no mesmo trabalho, igual a 0,92. Esse índice se aproxima do valor 1 quando a distribuição dos tipos de manchas se torna mais equilibrada. Portanto, na área de estudo, é possível considerar uma tendência de uniformidade na distribuição das manchas.

Quanto à diversidade encontrada para a área, cabe ressaltar que a variedade de ambientes sugere uma diversidade biótica maior, pois, conforme afirma Carmo (op cit.), a presença de manchas em estágios sucessionais diferentes contribui para a manutenção da diversidade de espécies. No entanto, isso deve ser considerado para grandes áreas, em que as manchas são formadas pela dinâmica de perturbação natural das florestas, no sentido de uma evolução ecossistêmica. Contudo, considerando como objetivo da 
conservação da biodiversidade a manutenção dos ecossistemas naturais, no sentido de propiciar a proteção das espécies bióticas originais, mais significativa de que a diversidade de manchas deve ser a diversidade existente no interior das manchas.

Sendo assim, considerando que a variedade de espécies tende a aumentar durante as etapas do desenvolvimento da comunidade, dependentes dos nichos potenciais (BRASIL, 1994; Guapyassu, 1994; Degraaf e Miller, 1996; Botkin e Keller, 1998; Odum, 1997), as manchas de floresta na Morraria devem apresentar uma diversidade biótica mais expressiva e de interesse à conservação.

O índice de continuidade resultou em um valor igual a 3,72 para a Morraria. Se comparado ao índice de continuidade obtido para o estudo na Costa Rica, igual a 4,56, e levando-se em conta a análise de Carmo (2000) de que valores baixos refletem maiores níveis de descontinuidade ou de fragmentação, é possível considerar que a Morraria apresenta pouca continuidade de área, encontrando-se, portanto, fragmentada. Aliada a esse índice, a falta de conectividade na área é expressa pela ausência de ligação com outros fragmentos, dependendo principalmente da conectividade interna e da atividade de insetos como polinizadores e da avifauna como dispersores.

\section{CONCLUSÕES}

- A falta de conectividade provoca uma situação em que as manchas de paisagem ficam sujeitas a uma área restrita, sendo que os corredores ecológicos, além de proporcionar fluxo genético, podem minimizar impactos decorrentes de distúrbios e estabelecer um "cinturão verde" para limitar a expansão urbana, representando também um importante atrativo contemplativo, potencializando a vocação cênica da Morraria.

- A estrutura espacial e o padrão funcional da paisagem denotam como mais relevantes, para a conservação da biodiversidade, a existência de duas classes de manchas, constituídas de floresta e de estágios avançado e médio de sucessão, formando nove manchas individuais, mais expressivas pelos tamanhos e pelas tipologias.

- A matriz da paisagem é representada por uma mancha de floresta que domina a área, sendo um fator favorável à conservação da biodiversidade local.

- A manutenção da biodiversidade está condicionada à presença das manchas de floresta, as quais contribuem também para uma maior diversidade biótica em função da existência de mais nichos potenciais.

- A situação natural da área como fragmento costeiro é intensificada pela interferência do entorno, sendo que o Oceano Atlântico influencia mais em relação aos distúrbios naturais, enquanto a planície urbanizada mais pelas atividades predatórias, provenientes principalmente das atividades de caça e de retirada de plantas ornamentais e de palmito.

- $\mathrm{Na}$ área também é significativo o impacto decorrente da estrada de terra que atravessa a Morraria, atuando como corredor com função negativa de filtro e de sumidouro, sendo os corredores curso d'água e mata ciliar os que mais beneficiam a conservação da biodiversidade, em função de atuarem como hábitat e condutor.

\section{REFERÊNCIAS}

BOTKIN, D. B.; KELLER, E. A. Environmental science: earth as a living planet. 2.ed. New York: J. Wiley \& Sons. 1998. 649p.

BRASIL. Resolução CONAMA n. 04. Estabelece a definição de vegetação primária e secundária nos estágios inicial, médio e avançado de regeneração da Mata Atlântica. Brasília, 1994.

BUREL, F.; BAUDRY, J. Ecologia del paisaje: conceptos, métodos y aplicaciones. Madrid: MundiPrensa, 2002. 353p.

CARMO, A. P. C. Evaliación de um paisaje fragmentada para la conservación y recuperación de biodiversidad. Costa Rica, 2000, 133p. Tese (Magister Scientiae) - Centro Agronômico Tropical de Investigación y Enseñanza. 
DEGRAAF, R. M.; MILlER, R. I. Conservation of Faunal Diversity in Forest Landscapes. London: Chapman \& Hall, 1996. 633p.

ELKIE, P. C.; REMPEL, R. S.; CARR, A. P. Patch analyst user's manual: A tool for quantifying landscape structure. Ontario: Ontario Ministry of Natural Resources, 1999. 22p.

FUNDAÇÃO ESTADUAL DE ENGENHARIA DO MEIO AMBIENTE. Vocabulário básico do meio ambiente. 4. ed. Rio de Janeiro: Petrobrás, 1992. 246p.

FILGUEIRAS, T. S.; NOGUEIRA, P. E.; BROCHADO A. L.; GUALA II, G. F. Caminhamento: um método expedito para levantamentos florísticos qualitativos. Cadernos de Geociências, Rio de Janeiro, n.12, 1994.

FORMAN, R. T. T.; GODRON, M. Patches and structural components for a landscape ecology. Bioscience, Washington, EUA, v.31, n.10, p.733-740, 1981.

FORMAN, R. T. T.; GODRON, M. Landscape ecology. New York: John Wiley \& Sons, 1986. 619p.

FORMAN, R. T. T. Land mosaics: The ecology of landscapes and region. New York: Cambridge Press, 1995. 632p.

FORMAN, R. T. T.; COLLINGE, S. K. The spacial solution to conserving biodiversity in landscapes and regions. In: DEGRAAF, R. M.; MILLER, R. I. Conservation of Faunal Diversity in Forest Landscapes. London: Chapman \& Hall, 1996. p.537-568.

GASCON, C.; LAURENCE, W. F.; LOVEJOY, T. E. Fragmentação florestal e biodiversidade na Amazônia Central. In: GARAY, I; DIAS, B. Conservação da biodiversidade em ecossistemas tropicais. Petrópolis: Vozes, 2001, p.112-127.

GODRON, M. The natural hierarchy of ecological system. In: KLIJN, F. Ecosystem classification for environmental management. Netherlands: Kluwer Academic, 1994. p.69-83.

GUAPYASSÚ, M. S. Caracterização fitossociológica de três fases sucessionais de uma Floresta Ombrófila Densa Submontana, Morretes - Paraná. Curitiba, 1994. 150p. Dissertação (Mestrado em Conservação da Natureza) - Setor de Ciências Agrárias, Universidade Federal do Paraná.

HOBBS, R. J.; SAUNDERS, D. A.; LOBRY de BRUYN, L. A.; MAIN, A. R. Changes in Biota. In: HOBBS, R. J.; SAUNDERS, D. A. Reintegrating Fragments Landscapes: towards sustainable production and nature conservation. New York: Springer, 1993. p.65-106.

JORDANA, J. C. C. Curso de introducción al paisage: metodologias de valoración. Curitiba: Universidade Federal do Paraná/Universidad de Cantábria, 1992, 60p. Apostila.

MALANSON, G. P. Riparian landscapes. New York: Cambridge University Press, 1995. 227p.

MARENZI, R. C. Estudo da Valoração da Paisagem e Preferências Paisagísticas no Município da Penha - SC. Curitiba, 1996. 119p. Dissertação (Mestrado em Conservação da Natureza) - Setor de Ciências Agrárias, Universidade Federal do Paraná.

MATTEUCCI, S. D. La cuantificación de la estructura del paisaje. In: MATTEUCCI, S. D.; BUZAI, G. D. Sistemas ambientales complejos: herraminetas de analisis especial. Buenos Aires: Universitaria, 1998. p.271-292.

MAZZER, A. M. Aspectos da ecologia da paisagem da Ilha do Campeche (Florianópolis-SC): uma contribuição ao manejo insular. Florianópolis, 2001. 242p. Dissertação (Mestrado em Engenharia Ambiental) - Departamento de Engenharia Ambiental, Universidade Federal de Santa Catarina.

ODUM, E. Fundamentos de Ecologia. 3. ed. Lisboa: Fundação Calouste Gulbenkian, 1997. 927p.

PIRES, P. S. Avaliação da qualidade visual da paisagem na região carbonífera de Criciúma-SC. Curitiba, 1993. 96p.Dissertação (Mestrado em Engenharia Florestal) - Setor de Ciências Agrárias, Universidade Federal do Paraná. 
POLETTE, M. Paisagem: uma reflexão sobre um amplo conceito. Turismo - Visão e Ação, Itajaí, ano 2, n.3, p.83-96, 1999.

PORTO, M. L. Ecologia da Paisagem. Porto Alegre: UFRG, 1999.

PRIMACK, R. B.; RODRIGUES, E. Biologia da conservação. Londrina: E. Rodrigues, 2001. 328p.

ROCHA, C. H. Ecologia da Paisagem e Manejo Sustentável em Bacias Hidrográficas: estudo do Rio São Jorge nos Campos Gerais do Paraná. Curitiba, 1995. 176p. Dissertação (Mestrado em Solos) - Setor de Ciências Agrárias, Universidade Federal do Paraná.

SCHWABE, A. Vegetation complexes can be used to differentiate landscape units. In: RUMELHART, M. Phytosociologie et paysage. Berlin: J. Cramer, 1991 p.260-280.

TERRADAS, J. Ecologia de la vegetacion. Barcelona: Omega, 2001. 703p.

TROPPMAIN, H. Ecologia da paisagem: uma retrospectiva. In: FÓRUM DE DEBATES ECOLOGIA DA PAISAGEM E PLANEJAMENTO AMBIENTAL, 1. 2000, Rio Claro. Anais... Rio Claro: Sociedade de Ecologia do Brasil, 2000.

TURNER, S. J.; O'NELL, R. V.; CONLEY. W.; CONLEY. M. R.; HUMPHRIES. Pattern and scale: Statistics for landscape ecology. In: TURNER; M. G.; GARDNER, R. H. Quantitative methods in landscape ecology: the analysis and interpretation of landscape heterogeneity. New York: Springer. 1991, p.17-51.

TURNER; M. G.; DALE, V. H.; GARDNER, R. H. Predicting across scales: theory development and testing. Landscape Ecology, Dordrecht, Holanda, v.3, n.3/4, p.245-242. 1989.

TURNER; M. G.; GARDNER, R. H. Quantitative methods in landscape ecology: An introduction. In: TURNER; M. G.; GARDNER, R. H. Quantitative methods in landscape ecology: the analysis and interpretation of landscape heterogeneity. New York: Springer. 1991. p.3-17.

UNIÃO INTERNACIONAL PARA A CONSERVAÇÃO DA NATUREZA. Estratégia mundial para a conservação: a conservação dos recursos vivos para um desenvolvimento sustentado. São Paulo, CESP, 1984, II 1v.

ZONNEVELD, I. Landscape ecology and ecological networks. In: COOK, E. A.; VAN LIER H. N. Landscape planning and ecological networks. Amsterdan: Elsevier Science, 1994. p.13-20. 